\title{
Design of wide band slotted microstrip patch antenna with defective ground structure for ku band
}

\author{
Akhila John Davuluri, P. Siddaiah \\ Department of Electronics and Communication Engineering, Acharya Nagarjuna University, Andhra Pradesh, India
}

\begin{tabular}{|c|c|}
\hline Article Info & ABSTRACT \\
\hline Article history: & This paper proposes a microstrip patch antenna (MSPA) in the Ku band for \\
\hline Received Feb 3, 2020 & $40 \mathrm{~mm} \times 48 \mathrm{~mm} \times 1.59 \mathrm{~mm}$ and is fed with a coaxial cable of $50 \Omega$ impedance. \\
\hline Revised Jul 27, 2020 & The proposed antenna has a wide bandwidth of $3.03 \mathrm{GHz}$ ranging from \\
\hline Accepted Sep 25, 2020 & $\begin{array}{l}12.8 \mathrm{GHz} \text { to } 15.8 \mathrm{GHz} \text {. To realize the characteristics of wideband the techniques of } \\
\text { defective ground structure (DGS) and etching slots on the radiating element }\end{array}$ \\
\hline Keywords: & $\begin{array}{l}\text { are adopted. The antenna is modeled on the FR4 substrate. A basic circular } \\
\text { patch is selected for the design of a dual-frequency operation and in the next }\end{array}$ \\
\hline DGS & step DGS is introduced into the basic antenna and enhanced bandwidth is \\
\hline $\mathrm{Ku}$ band & $\begin{array}{l}\text { achieved at both the frequencies. To attain wider bandwidth two slots are } \\
\text { etched on the radiating element of which one is a square ring slot and the }\end{array}$ \\
\hline MSPA & second one is a circular ring slot. The novelty of the proposed antenna is a \\
\hline Ring Slot & miniaturized design and unique response within the Ku band region which is \\
\hline Wideband & $\begin{array}{l}\text { applicable for wireless UWB applications with VSWR }<2 \text { and an average } \\
\text { gain of } 3.6 \mathrm{~dB} \text {. }\end{array}$ \\
\hline
\end{tabular}

This is an open access article under the $\underline{C C B Y-S A}$ license.

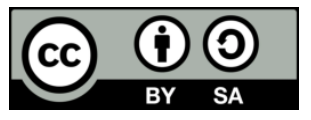

\section{Corresponding Author: \\ Akhila John Davuluri \\ Department of Electronics and Communication Engineering \\ Acharya Nagarjuna University \\ Nagarjuna Nagar, Guntur, Andhra Pradesh, India \\ Email: akhilajohndavuluri@gmail.com}

\section{INTRODUCTION}

In the bygone few eons, the microstrip antennas have been used in incredible applications in the areas of radars, satellite communications, Radio frequency identification, telemetry, aerospace communications, etc. The microstrip antennas in conventional form have certain limits like thin bandwidth, polarization impurity, and huge size to exhibit superior performance. Usually, each patch antenna operates at a frequency for a particular application but with the fast advancements in the current wireless system, the requirement of wider bandwidth for numerous applications using a single antenna became possible. On the other side, there is a pronounced demand for wireless devices which are light in weight, minute, and easy to manufacture at low cost. At present, in radar and space applications, microstrip patch antenna (MPSA) has great demand due to its low profile, mechanical strength, and compatibility with MMIC designs. These MSPA are conformable in planar and non-planar surfaces. The limitations like false feed radiation, low power, low efficiency, and the huge level of cross-polarization radiation are possible Hexagonal shape monopoles offer a wider bandwidth than the rectangular and square monopoles. Though these shapes contribute much lesser bandwidth than elliptical and circular patterns, although these bandwidths are sufficient for several applications [1]. Attaining multiband and dual-band characteristics is very advantageous, specifically at higher frequencies. Over the period the dual-band antennas are upgraded to 
countenance the challenges of present-day wireless systems that are proficient in assimilating multiple communication standards on to a particular system [2].

To overcome the precincts and depravations, investigators proposed and revealed many techniques like slots on the patch surface, use of thicker substrate electrically, coax feed stacked antenna, and utilization of several feeding and impedance matching techniques [3-7]. A Penta-Gasket-Koch technique in Fractal antenna using three iterations are implemented to obtain a good input impedance matching and linear phase all through the passband from 1.5-20 GHz [8]. Radiating edges of the circular slotted patch antenna operate at two frequencies with impedance bandwidth improvement of $26.2 \%$ and $22.2 \%$ respectively are presented [9]. A printed compact antenna, of size $30 \times 22 \mathrm{~mm}^{2}$, are imprinted on both sides of an FR4 substrate. The ground contains triangle-shaped slots on the uppermost edges, assists to improve the impedance bandwidth to $12.82 \mathrm{GHz}$ [10]. At present wide bandwidth requirement is of the great demand for modern wireless communication applications. Generally, each antenna performs its function at a single operating frequency, more antennas are required for different applications which causes space problems. A significant research effort has done in the multiband antennas design to avoid spacing problems [11, 12]. Slits or slots assimilated on the ground surface of microwave planar circuits are stated as defected ground structure (DGS). DGS is approved as an excellent technique for enhancing the parameters of the circuits like narrow bandwidth, small gain, cross-polarization, and so on $[13,14]$. A tri-band circular patch microstrip antenna has slots of two inverted U shape and a CPW feed with discrete DGS profile shapes of E, F, and U are used. Due to the DGS the performance parameters of the antennas like return loss, gain VSWR, and bandwidth is improved [15]. With the advent of technological encroachments, a variety of design techniques for controlling electronically radiation pattern and enhancement of radiation in boresight for different frequency bands were developed in antennas [16-19]. FR4 based polygonal patch antenna and a CPW feed antenna are desined to resonate at UWB [20, 21]. Simple Ku band antenna resonates at $15 \mathrm{GHz}$ is designed with a gain of $9.2 \mathrm{~dB}$ is presented [22]. Planar arrays in $\mathrm{Ku}$ band are designed to for applications in Several low-cost feeding network configurations have been tested [23-25]. There is a vast scope to explore the miniature antennas which provide wider bandwidth, higher gain, and efficiency. In this paper, a microstrip patch antenna is proposed which has a wide bandwidth of $3.03 \mathrm{GHz}$ ranging from $12.8 \mathrm{GHz}$ to $15.83 \mathrm{GHz}$. The technique of defective ground structure (DGS) and etching slots on the radiating element are used to achieve bandwidth.

\section{RESEARCH METHOD}

The antenna is designed on FR4 material of dielectric constant 4.4, the thickness of $1.59 \mathrm{~mm}$, and loss tangent value of 0.02 . The overall size of the antenna is $40 \times 48 \times 1.59 \mathrm{~mm}$ and is fed with a coaxial cable of $50 \Omega$ impedance. Initially, three basic antennas were designed with different patches, of which one is a circular patch, second is a heptagonal patch and the third is a rectangular patch shown in Figure 1.

In step 2, DGS is introduced into the three basic antennas and the performance of the antennas in terms of the impedance is analyzed and shown in Figure 2. The defected ground structure contains a square ring slot at the center of the ground and four square slots with a circle at the center at all the four corners of the ground.

In step 3 to obtain the wide bandwidth, two slots are etched on the patch of which one is a square ring slot and then the second one is a circular ring slot and next with the combination of both the slotted rings, the performance metrics are studied. The dimensions of the radiating elements of the three basic patch antennas Circle, Heptagon, and rectangle are estimated from the following equations given below. The dimensions of the heptagon are calculated from the following formulas;

$$
\mathrm{R}_{2}=\mathrm{R}_{1} \cos (\theta / 2) \approx 0.9 \mathrm{R}_{1}
$$

where $\theta$ it is equal to $51.428^{\circ}$.

The area $A_{1}$ of the triangular shown in Figure 1.

$$
\begin{aligned}
& \mathrm{A}_{1}=0.5 \mathrm{~B} \times \mathrm{R}_{2}=0.391 \times \mathrm{R}_{1}{ }^{2} \\
& \mathrm{~A}=7 \times \mathrm{A}_{1}=2.737 \mathrm{R}_{1}^{2} \\
& 2 \pi \mathrm{rl}=2.737 \mathrm{R}_{1}^{2}
\end{aligned}
$$


The schematic of the heptagonal patch is shown in Figure 3. Where ' $r$ ' is the equivalent radius of the wire, ' $\mathrm{l}$ ' is the height of the wire, and ' $\mathrm{R}_{1}$ ' is the radius of the heptagonal patch. Further, the resonant frequency formulas are used from [15].

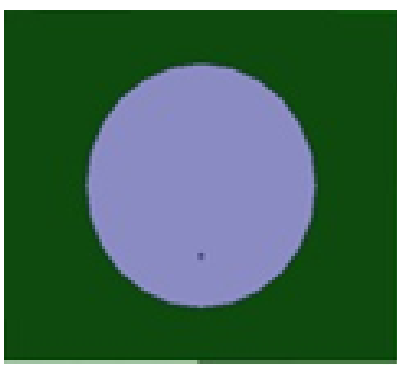

(a)

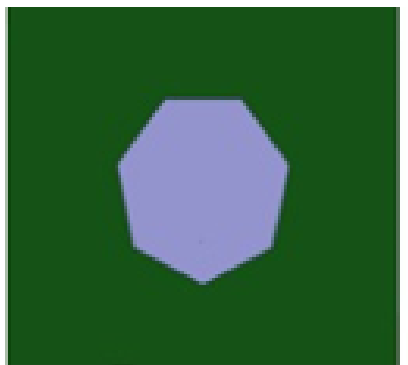

(b)

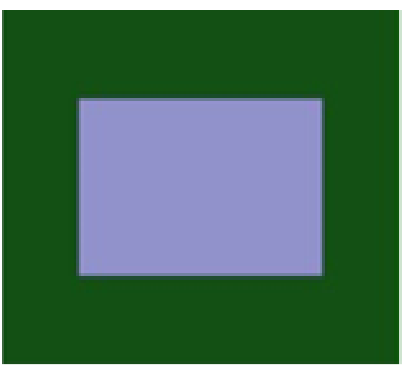

(c)

Figure 1. Represents the basic microstrip patch antennas, (a) antenna 1, (b) antenna 2, (c) antenna 3

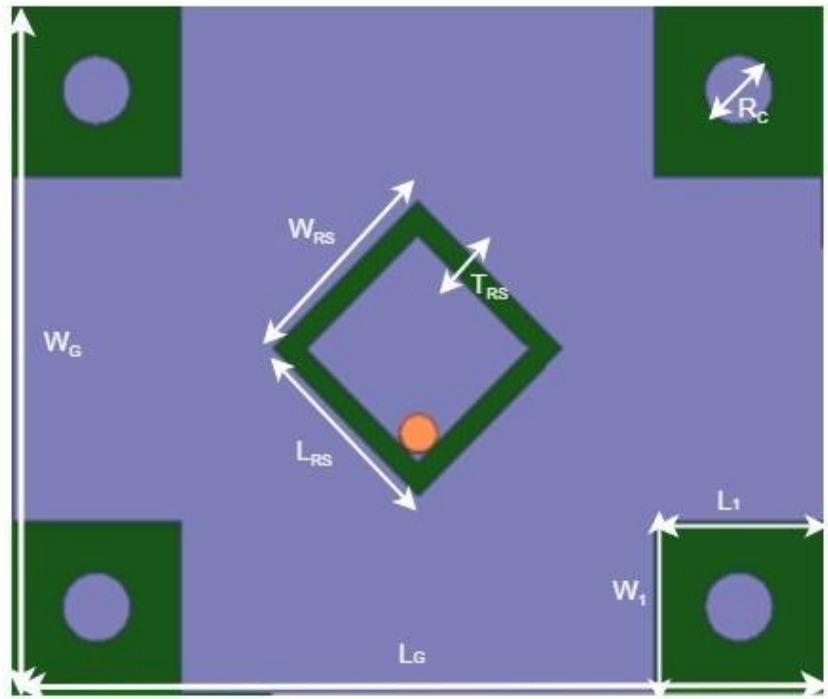

Figure 2. Proposed defective ground structure (DGS)
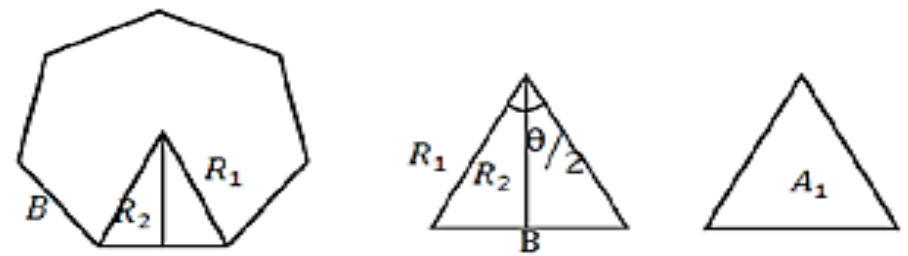

Figure 3. The schematic of heptagonal patch

The dimensions of the rectangular patch are determined from the following formulas;

$$
\begin{aligned}
& W=\frac{c}{2 f_{o} \sqrt{\frac{\left(\varepsilon_{r}+1\right)}{2}}} \\
& \varepsilon_{\text {eff }}=\frac{\varepsilon_{r}+1}{2}+\frac{\varepsilon_{r}-1}{2}\left[1+12 \frac{h}{W}\right]^{-\frac{1}{2}}
\end{aligned}
$$




$$
\begin{aligned}
& L_{e f f}=\frac{c}{2 f_{o} \sqrt{\varepsilon_{e f f}}} \\
& \Delta \mathrm{L}=0.412 \mathrm{~h} \frac{\left(\varepsilon_{e f f}+0.3\right)\left(\frac{W}{h}+0.264\right)}{\left(\varepsilon_{e f f}-0.258\right)\left(\frac{W}{h}+0.8\right)}
\end{aligned}
$$

The actual patch length is calculated using (8);

$$
L=L_{e f f}-2 \Delta \mathrm{L}
$$

The dimensions of the circular patch are enumerated from the following formulas;

$$
\mathrm{a}=\mathrm{F}\left\{1+\frac{2 \boldsymbol{h}}{\pi \boldsymbol{F} \varepsilon_{r}}\left[\ln \left(\frac{\pi \boldsymbol{F}}{2 \boldsymbol{h}}\right)+1.7726\right]\right\}^{-1 / 2}
$$

where,

$$
\begin{aligned}
& \mathrm{F}=\frac{8.791 \times 10^{9}}{f_{r} \sqrt{\varepsilon_{r}}} \\
& a_{e}=\mathrm{a}\left\{1+\frac{\mathbf{2 h}}{\pi \boldsymbol{a} \varepsilon_{r}}\left[\ln \left(\frac{\pi \boldsymbol{a}}{2 \boldsymbol{h}}\right)+1.7726\right]\right\}^{1 / 2}
\end{aligned}
$$

Figure 4 presents the return loss plot of the Antenna 1 Antenna 2 and Antenna 3. It is observed that the Antenna 1 is has a dual-frequency of operation while the remaining two antennas have only a single frequency of operation. As the coaxial feed will excite the modes of the patch antenna, but only one or few are excited depending on the structure of the patch and feed point location, the resonating frequencies are observed. Therefore circular patch is chosen over the heptagonal and rectangular patches.

Figure 5 shows the VSWR of Antenna 1 Antenna 2 and Antenna 3. It is observed that Antenna 1 is having a dual-frequency of operation at $13.06 \mathrm{GHz}$ and $15 \mathrm{GHz}$ while the remaining two antennas are resonating at $15 \mathrm{GHz}$. From the above graphs, it is observed that the impedance response is good in the case of a circular patch. As the coaxial probe feed will excite the modes on the patch, according to the geometry of the patch the resonating frequencies are observed.

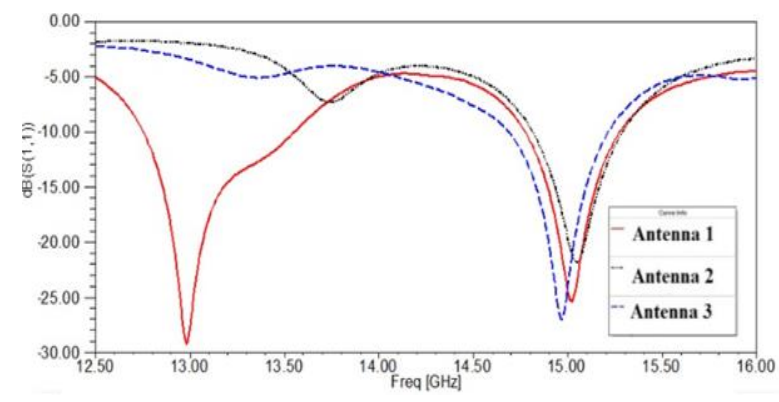

Figure 4. Return loss plot of basic microstrip patch antennas

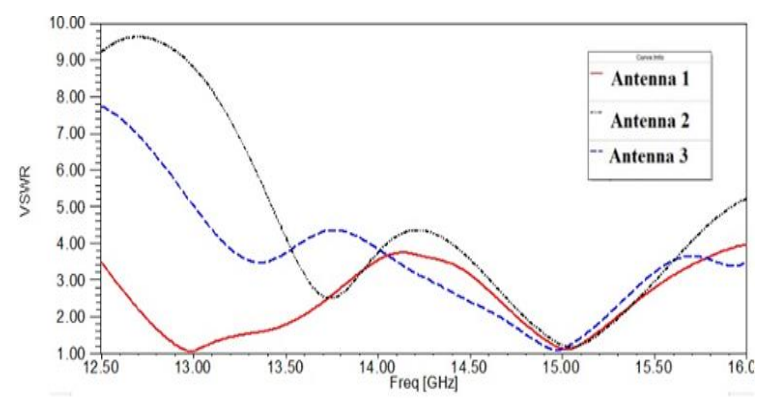

Figure 5. VSWR plot of basic microstrip patch antennas

To surge the performance of the antenna, the technique of slotting is applied on the ground. The DGS consists of a slotted square ring at the center of the ground and four square slots with a circle at the center at all the four corners of the ground are used instead of normal ground plane. A planar radiating structure with alterations in the ground was made to develop the performance of the antenna. The dimensionsof the proposed defective ground structure (DGS) are shown in Table 1.

The schematics view of basic patch antennas 1,2 and 3 are modified by replacing the normal ground plane with DGS are shown in Figure 6. Figure 7 shows the return loss plot of the DGS Antennas 4, 5, 6. It is observed that the Antenna 4 is having a dual-frequency of operation at $12.7 \mathrm{GHz}$ and $15.0 \mathrm{GHz}$. Figure 8 
depicts the VSWR plot of the DGS Antennas 4, 5, 6. It is observed that the Antenna 4 is having VSWR $<2$ for the frequencies of $12.7 \mathrm{GHz}$ and $15.0 \mathrm{GHz}$. From the above outcomes, it is observed that the impedance response is better in the case of a circular patch antenna with and without DGS. To enhance the performance of the antennas, slots are imprinted on the radiating element. A planar structure with changes in the radiating element was considered to progress the performance of the antenna parameters like return loss, VSWR, and Gain.

Table 1. Dimensions of the proposed DGS

\begin{tabular}{ccc}
\hline Parameter & Description & $\begin{array}{c}\text { Values } \\
(\mathrm{mm})\end{array}$ \\
\hline $\mathrm{W}_{\mathrm{G}}$ & $\begin{array}{c}\text { Width of the Ground } \\
\text { Length of the Ground }\end{array}$ & 40 \\
$\mathrm{~L}_{\mathrm{G}}$ & $\begin{array}{c}\text { The diameter of dots on the corners } \\
\text { of the ground }\end{array}$ & 2 \\
$\mathrm{R}_{\mathrm{C}}$ & Width of corner slot of the ground & 10 \\
& $\begin{array}{c}\text { Length of corner slot of the ground } \\
\mathrm{W}_{1}\end{array}$ & 10 \\
$\mathrm{~L}_{1}$ & The thickness of the diamond slot & 2.83 \\
$\mathrm{~T}_{\mathrm{RS}}$ & on the ground & \\
& Length of Rectangular Slot & 15.14 \\
$\mathrm{~L}_{\mathrm{RS}}$ & Width of Rectangular Slot & 15.14 \\
$\mathrm{~W}_{\mathrm{RS}}$ &
\end{tabular}

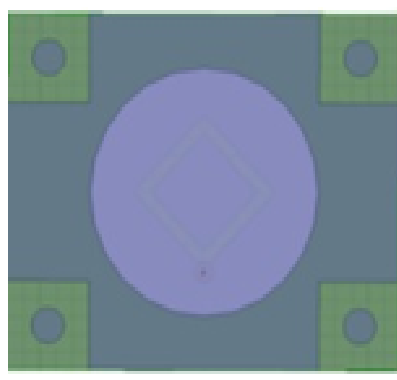

(a)

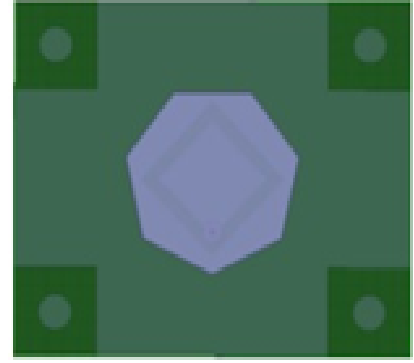

(b)

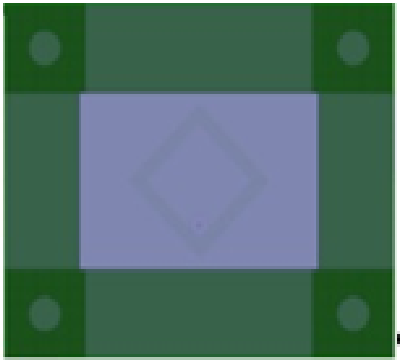

(c)

Figure 6. Basic microstrip patch antennas with proposed DGS, (a) antenna 4, (b) antenna 5, (c) antenna 6

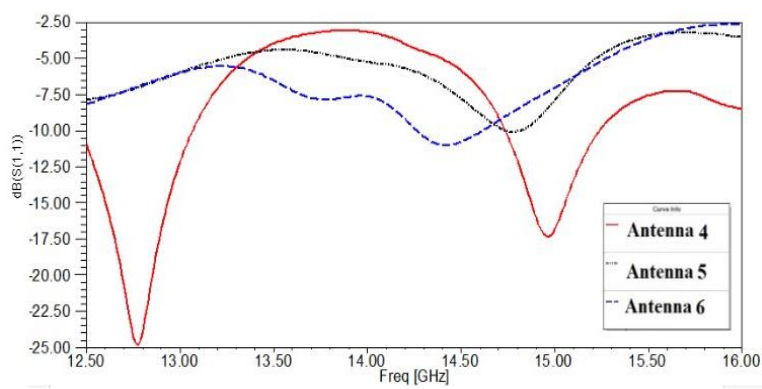

Figure 7. Return loss plot of basic microstrip patch antennas with proposed DGS

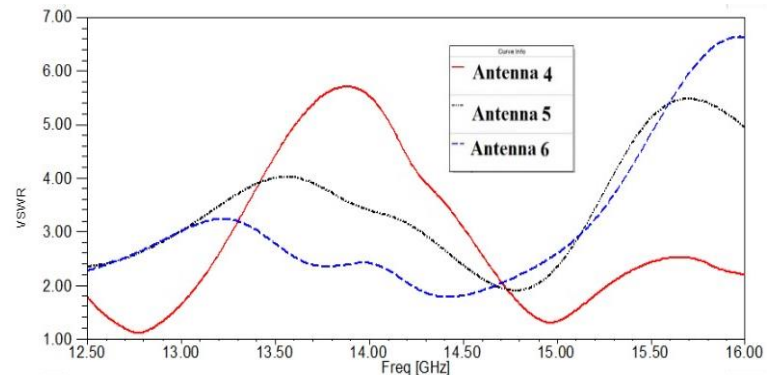

Figure 8. VSWR plot of basic microstrip patch antennas with proposed DGS

\section{RESULTS AND ANALYSIS}

The design of a slotted patch $\mathrm{Ku}$ band patch antenna with DGS for satellite communications is presented. The presented antenna is a single layer circular patch configuration where a thin layer of FR4 substrate used for etching the microstrip patch element. Antenna 7 contains only a slotted square ring and Antenna 8 contains an only slotted circular ring. Antenna 9 contains both the square and circular slotted rings.

Figure 9 shows the sequence if developments on the circular patch DGS antenna with slotted patch surface. Figure 10 shows the return loss plot of the Antennas 7, 8, 9 with DGS and slots. It is observed that the antenna 7 is has a very low level of impedance matching while the antenna 8 has a wide bandwidth but the antenna 9 has a much wider bandwidth of $3.03 \mathrm{GHz}$ ranging from $12.8 \mathrm{GHz}$ to $15.83 \mathrm{GHz}$. The current path length is enlarged due to slots etched on the patch surface, which leads to additional inductance in series. 
The wide bandwidth is generated as the resonant circuits become coupled. Figure 11 depicts the VSWR plot of the Antenna 9 model with DGS and the slotted patch. The proposed antenna is having wide bandwidth of $3.03 \mathrm{GHz}$ ranging from $12.8 \mathrm{GHz}$ to $15.83 \mathrm{GHz}$. The dimensions of the proposed slots on the patch are shown in Table 2.

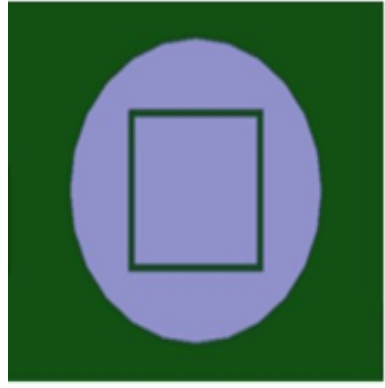

(a)

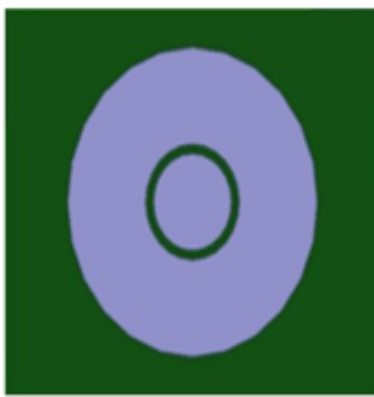

(b)

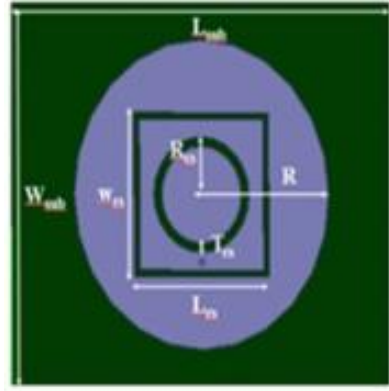

(c)

Figure 9. The sequence of the proposed slotted patch with dgs, (a) antenna 7, (b) antenna 8, (c) antenna 9

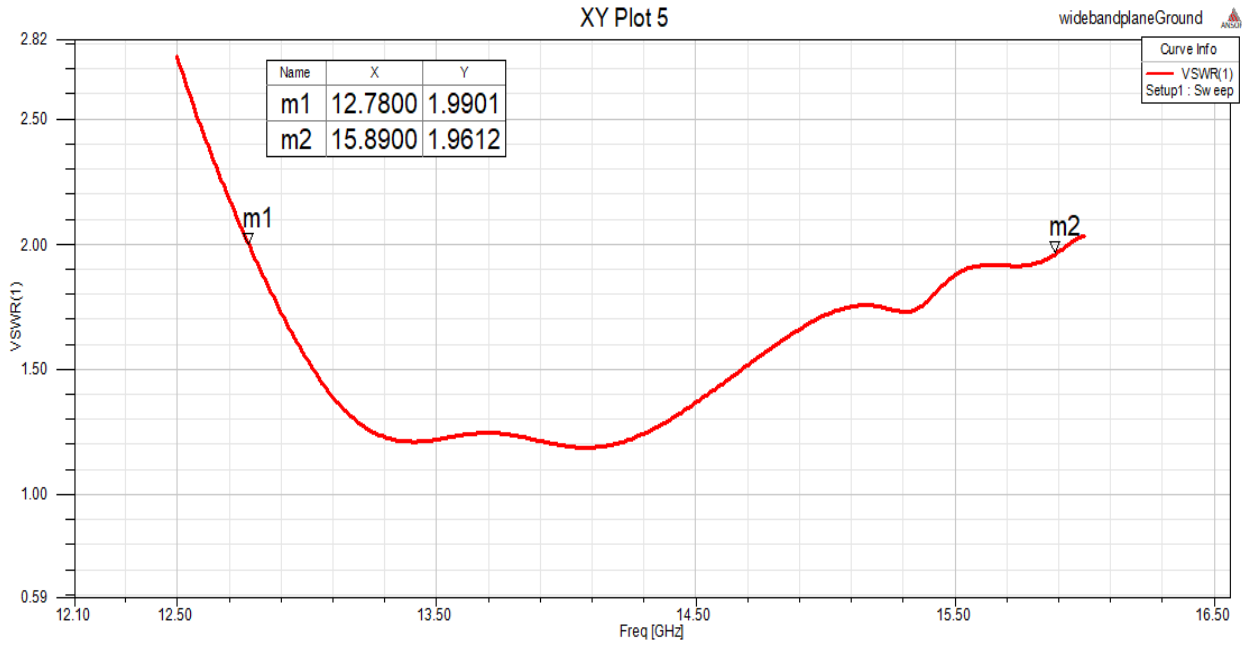

Figure 10. The return loss plot of slotted patch antennas with proposed DGS

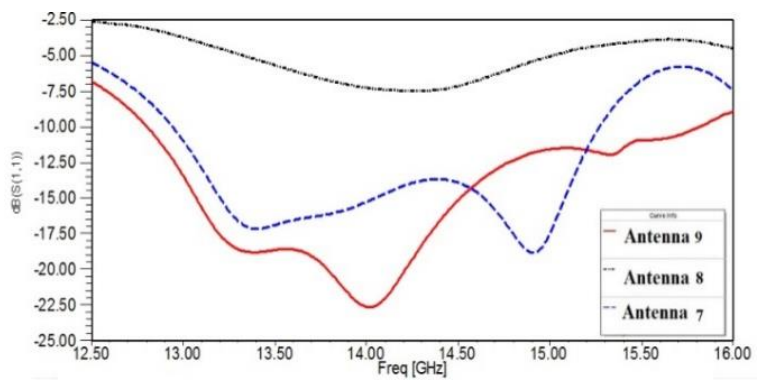

Figure 11. The VSWR of slotted patch antenna 9 with proposed DGS at $16 \mathrm{GHz}$
Table 2. Dimensions of the proposed slotted patch

\begin{tabular}{ccc} 
Parameter & Description & $\begin{array}{c}\text { Values } \\
(\mathrm{mm})\end{array}$ \\
\hline $\mathrm{W}_{\text {sub }}$ & Width of the Substrate & 40 \\
$\mathrm{~L}_{\text {sub }}$ & Length of the Substrate & 48 \\
$\mathrm{R}$ & Patch Radius & 16 \\
$\mathrm{~W}_{\mathrm{rs}}$ & Rectangular Slot Width & 17 \\
$\mathrm{~L}_{\mathrm{rs}}$ & Rectangular Slot & 17 \\
$\mathrm{R}_{\mathrm{CS}}$ & Length & 12 \\
$\mathrm{~T}_{\mathrm{CS}}$ & Radius of Circular Slot & Thickness of Circular \\
$\mathrm{H}$ & Slot & 1 \\
& Height of the Substrate & 1.59 \\
\hline
\end{tabular}

Figure 12 presents the gain plot of the proposed wideband antenna 9 at frequencies of $16 \mathrm{GHz}$ and Observed a gain of $3.67 \mathrm{~dB}$. Figure 13 presents the radiation in E-plane pattern and H-plane patterns of the antenna 9 model at a frequency of $16 \mathrm{GHz}$. Figure 14 depicts the distribution of surface currents on the radiating patch and the ground plane. Figure 15 illustrates the return loss plot of the proposed antenna 9 at 
three feeding locations. Here it is observed that depending upon the position of the feeding point a wide bandwidth and triple frequency response are seen. Parametric analysis is performed on feed location variable in high-frequency structural simulator (HFSS) software and observed that at (0.7) the antenna is resonating at triple frequencies and at feed position (0.3) wide bandwidth is observed. Table 3 presents the performance assessment of the proposed antenna with referred antennas from the literature. From this table, it is firmly agreed that the performance of the proposed antenna is much better in terms of gain with $3.67 \mathrm{~dB}$ and the smaller in size than the reported UWB antennas.

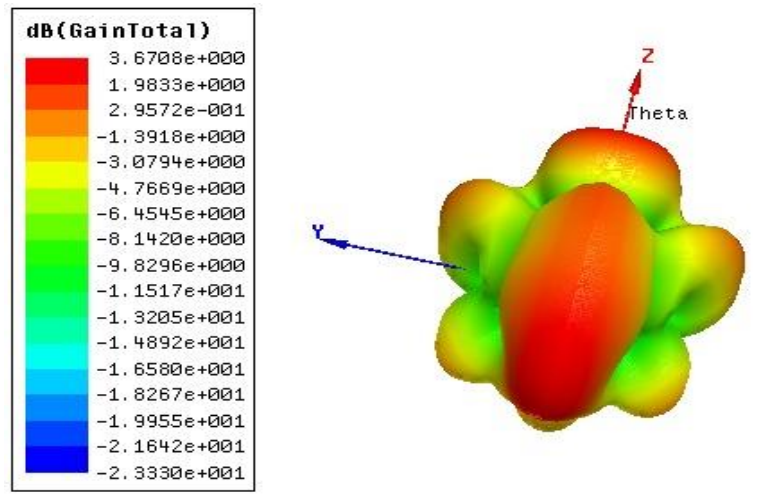

Figure 12. 3D gain proposed slotted patch antenna 9 with DGS at $16 \mathrm{GHz}$
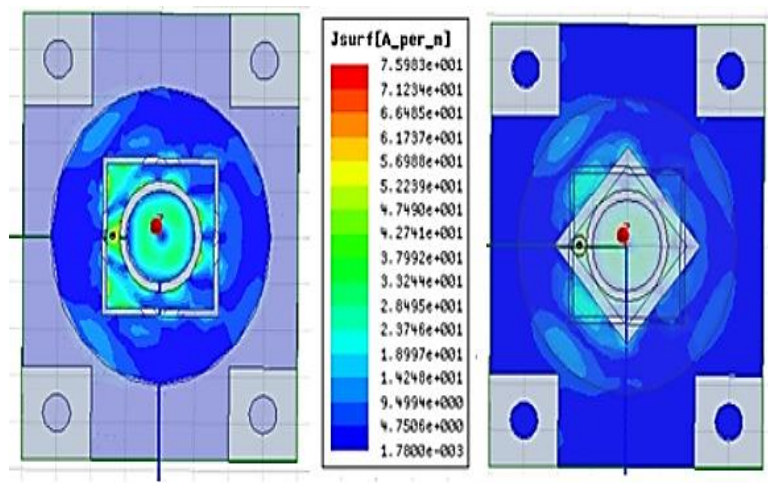

Figure 14. Surface currents J surface [a-per m]

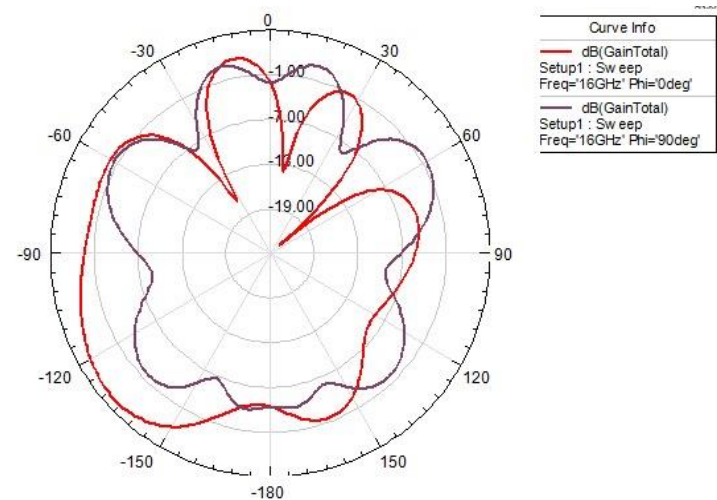

Figure 13. Radiation patterns of E-plane (xoz) and H-plane

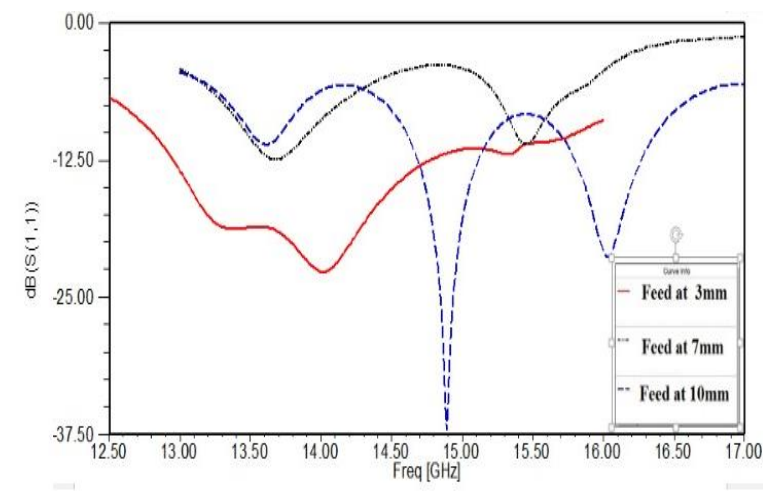

Figure 15. Returnloss plot of proposed antenna 9 with different feeding locations

Table 3. Comparison of proposed antenna 9 performance with other referred antennas

\begin{tabular}{|c|c|c|c|c|c|}
\hline Ref. & Substrate & Antenna Area (mm2) & No. of Bands & Resonant Frequency $(\mathrm{GHz})$ & Gain \\
\hline [4] & RT Duroid 5880 & $43 \times 50 \times 1.6$ & 1 & $2.8 \mathrm{GHz}$ to $4.83 \mathrm{GHz}$ & $\begin{array}{c}2.79 \\
3.8\end{array}$ \\
\hline [6] & FR4 & $45 \times 54 \times 1.59$ & 1 & 12.57 to 16.67 & $\begin{array}{c}2.65 \\
3.1\end{array}$ \\
\hline [7] & FR4 & $25 \times 25 \times 1.6$ & 3 & $\begin{array}{c}3.03 \\
6.11 \\
11.78\end{array}$ & $\begin{array}{c}1.05 \\
1.115 \\
1.3\end{array}$ \\
\hline [20] & FR4 & $53 \times 38.5 \times 5$ & UWB & $\begin{array}{l}2.44 \\
5.25\end{array}$ & 2.1 \\
\hline [21] & FR4 & $25 \times 25 \times 1.6$ & 3 & $\begin{array}{c}3.03 \\
6.11 \\
11.78\end{array}$ & $\begin{array}{c}1.05 \\
1.15 \\
1.3\end{array}$ \\
\hline $\begin{array}{c}\text { Proposed } \\
\text { Antenna } 9\end{array}$ & FR4 & $40 \times 48 \times 1.59$ & UWB & $\begin{array}{c}12.8 \text { to } \\
15.83\end{array}$ & $\begin{array}{l}1.3 \\
3.67\end{array}$ \\
\hline
\end{tabular}




\section{CONCLUSION}

A low cost, wide bandwidth microstrip patch antenna ranging from $12.8 \mathrm{GHz}$ to $15.83 \mathrm{GHz}$ is proposed. The $3.03 \mathrm{GHz}$ bandwidth is generated by utilizing the techniques of defective ground structure (DGS) and etching slots on the radiating element. The analysis is performed on the selection of the shape of the patch and its performance with the proposed DGS is also studied, finally, a slotted circular patch antenna with DGS is analyzed. Enhancement of bandwidth is accomplished by etching with two ring slots on the radiating element and the effects of the ring slots are presented. With the achieved bandwidth and other antenna parameters, it is concluded that the proposed antenna is suitable for ultra wide-band wireless applications. The novelty of the proposed antenna is small in size and the impedance response is within the $\mathrm{Ku}$ band region with VSWR $<2$ and exhibits an average gain of $3.6 \mathrm{~dB}$.

\section{REFERENCES}

[1] Aggarwall, N. P., G. Kumar, and K. P. Ray, "Wide-band planar monopole antenna," in IEEE Transactions on Antennas and Propagation, vol. 46, no. 2, pp. 294-295, 1998.

[2] Kandwal, Abhishek, "Compact Dual Band Antenna Design for $\mathrm{Ku} / \mathrm{Ka}$ Band Applications," Advanced Electromagnetics, vol. 6, no. 4, pp. 1-5, 2017.

[3] Kumar, Girish, and Kamala Prasan Ray, "Broadband microstrip antennas," Artech house, 2003.

[4] Islam, Mohammad Tariqul, Mohammed Nazmus Shakib, and Norbahiah Misran, "Broadband EH shaped microstrip patch antenna for wireless systems," Progress In Electromagnetics Research, vol. 98, pp. 163-173, 2009.

[5] Ramadan, Ali Halim, et al., "A reconfigurable U-Koch microstrip antenna for wireless applications," Progress In Electromagnetics Research, vol. 93, pp. 355-367, 2009.

[6] Islam, Mohammad Tariqul, et al., "Design analysis of high gain wideband L-probe fed microstrip patch antenna," Progress In Electromagnetics Research, vol. 95, pp. 397-407, 2009.

[7] Islam, Mohammad Tariqul, et al., "Curve fitting based particle swarm optimization for UWB patch antenna," Journal of Electromagnetic Waves and Applications, vol. 23, no. 17-18, pp. 2421-2432, 2009.

[8] Chen, Zhi Ning, et al., "Small planar UWB antennas in proximity of the human head," IEEE Transactions on Microwave Theory and Techniques, vol. 54, no. 4, pp. 1846-1857, 2006.

[9] Tiang, Jun-Jiat, et al., "Circular microstrip slot antenna for dual-frequency RFID application," Progress in Electromagnetics Research, vol. 120, pp. 499-512, 2011.

[10] Azim, R., Mohammad Tariqul Islam, and Norbahiah Misran, "Ground modified double-sided printed compact UWB antenna," Electronics Letters, vol. 47, no. 1, pp. 9-11, 2011.

[11] Elsadek, Hala, and Dalia Nashaat, "Quad band compact size trapezoidal PIFA antenna," Journal of Electromagnetic Waves and Applications, vol. 21, no. 7, pp. 865-876, 2007.

[12] Azim, Rezaul, et al., "Planar UWB antenna with multislotted ground plane," Microwave and Optical Technology Letters, vol. 53, no. 5, pp. 966-968, 2011.

[13] Khandelwal, et al., "Defected ground structure: fundamentals, analysis, and applications in modern wireless trends," International Journal of Antennas and Propagation, vol. 2017, no. 1, pp. 1-22, 2017.

[14] Islam, M. M., and M. T. Islam, and M. RI Faruque, "Dual-Band Operation of a Microstrip Patch Antenna on a Duroid 5870 Substrate for Ku-and K-Bands," The Scientific World Journal, vol. 2013, no. 3, pp. 1-10, 2013.

[15] Kakkar, Ashna, and Shalini Sah, "A tri-band circular patch microstrip antenna with different shapes in DGS for Ku and K applications," 2017 2nd International Conference on Telecommunication and Networks (TEL-NET), Noida, 2017, pp. 1-5.

[16] Mohsen, Mowafak K., et al., "Electronically controlled radiation pattern leaky wave antenna array for (C band) application," TELKOMNIKA (Telecommunication, Computing, Electronics and Control), vol. 17, no. 2, pp. 573-579, 2019.

[17] Mohsen, Mowafak K., et al.,"Enhancement of boresight radiation for leaky wave antenna array," TELKOMNIKA (Telecommunication, Computing, Electronics and Control), vol. 17, no. 5, pp. 2179-2185, 2019.

[18] Mohsen, Mowafak Khadom, et al., "Control radiation pattern for half width Microstrip leaky wave antenna by using PIN Diodes," International Journal of Electrical and Computer Engineering (IJECE), vol. 8, no. 5, pp. 2959-2966, 2018.

[19] Mohsen, Mowafak K., et al., "Achieving fixed-frequency beam scanning with a microstrip leaky-wave antenna using double-gap capacitor technique," IEEE Antennas and Wireless Propagation Letters, vol. 18, no. 7, pp. 1502-1506, 2019.

[20] Manzini, Mauro, et al., "Polygonal patch antennas for wireless communications," IEEE transactions on vehicular technology, vol. 53, no. 5, pp. 1434-1440, 2004.

[21] Gautam, Anil Kr, Swati Yadav, and Binod Kr Kanaujia, "A CPW-fed compact UWB microstrip antenna," IEEE Antennas and Wireless propagation letters, vol. 12, pp. 151-154, 2013.

[22] Akhila J. D., et al.,"Performance Analysis of High Gain Ku Band Square Choke Ring Antenna for Multipath Mitigation," International Journal of Microwave and Optical Technology, vol. 13, no. 3, pp. 188-193, 2018.

[23] Lakrit, Soufian, et al., "A new small high-gain wideband rectangular patch antenna for $\mathrm{X}$ and $\mathrm{Ku}$ bands applications," Journal of Taibah University for Science, vol. 12, no. 2, pp. 202-207, 2018.

[24] Garcia-Marin, et al., "Planar Array Topologies for 5G Communications in Ku Band," IEEE Antennas and Propagation Magazine, vol. 61, no. 2, pp. 112-133, 2019.

[25] Liu, Shengying, et al., "A dual-band shared aperture antenna array in Ku/Ka-bands for beam scanning applications," IEEE Access, vol. 7, pp. 78794-78802, 2019. 


\section{BIOGRAPHIES OF AUTHORS}

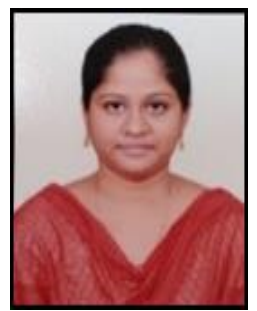

Research Scholar \& Asst. Professor D. Akhila John assistant professor in the Dept. of ECE at Acharya Nagarjuna University College of Engineering and Technology. She received B.Tech Degree in Electronics and Communication Engineering from JNT University, Hyderabad in 2005, and M.Tech Degree from VIT University, Vellore in 2008, and a doctoral student at Acharya Nagarjuna University. Her current research interests include antenna design, microstrip antennas for mobile and satellite applications, and medical applications.

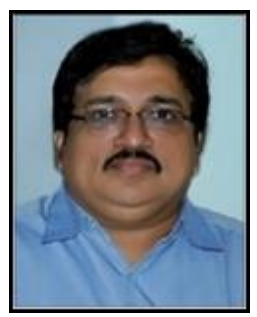

P. Siddaiah professor in the Dept. of ECE at Acharya Nagarjuna University. He obtained B.Tech degree in Electronics and Communication Engineering from JNTUA College of engineering in 1988. He received his M.Tech degree from SV University Tirupathi, completed his Ph.D. program in JNTU Hyderabad. He is the Chief Investigator for several outstanding Projects sponsored by Defense Organizations, AICTE, UGC \& ISRO. He is currently the Principal of the University College of Engineering and Technology, Acharya Nagarjuna University, Guntur, India. He has taught a wide variety of courses for UG \& PG and guided several projects. He has publications in National \& International Journals \& Conferences 